\title{
Pathogen and Pest Responses Are Altered Due to RNAi-Mediated Knockdown of GLYCOALKALOID METABOLISM 4 in Solanum tuberosum
}

\author{
Jamuna Risal Paudel, ${ }^{1,+}$ Charlotte Davidson, ${ }^{1}$ Jun Song, ${ }^{2}$ Itkin Maxim, ${ }^{3}$ Asaph Aharoni, ${ }^{4}$ and \\ Helen H. Tai ${ }^{1}$ \\ ${ }^{1}$ Agriculture and Agri-Food Canada, Fredericton Research and Development Centre, Fredericton, NB, Canada; ${ }^{2}$ Agriculture and \\ Agri-Food Canada, Kentville Research and Development Centre, Kentville, NS, Canada; ${ }^{3}$ Life Sciences Core Facilities; and \\ ${ }^{4}$ Department of Plant and Environmental Sciences, Weizmann Institute of Science, Rehovot, Israel
}

Accepted 4 August 2017.

\begin{abstract}
Steroidal glycoalkaloids (SGAs) are major secondary metabolites constitutively produced in cultivated potato Solanum tuberosum, and $\alpha$-solanine and $\alpha$-chaconine are the most abundant SGAs. SGAs are toxic to humans at high levels but their role in plant protection against pests and pathogens is yet to be established. In this study, levels of SGAs in potato were reduced by RNA interference (RNAi)-mediated silencing of GLYCOALKALOID METABOLISM 4 (GAME4)—a gene encoding cytochrome P450, involved in an oxidation step in the conversion of cholesterol to SGA aglycones. Two GAME4 RNAi lines, T8 and T9, were used to investigate the effects of manipulation of the SGA biosynthetic pathway in potato. Growth and development of an insect pest, Colorado potato beetle (CPB), were affected in these lines. While no effect on CPB leaf consumption or weight gain was observed, early instar larval death and accelerated development of the insect was found while feeding on leaves of GAME4 RNAi lines. Modulation of SGA biosynthetic pathway in GAME4 RNAi plants was associated with a larger alteration to the metabolite profile, including increased levels of one or both the steroidal saponins or phytoecdysteroids, which could affect insect mortality as well as development time. Colonization by Verticillium dahliae on GAME4 RNAi plants was also tested. There were increased pathogen levels in the T8 GAME4 RNAi line but not in the T9. Metabolite differences between $\mathrm{T} 8$ and $\mathrm{T} 9$ were found and may have contributed to differences in $V$. dahliae infection. Drought responses created by osmotic stress were not affected by modulation of SGA biosynthetic pathway in potato.
\end{abstract}

Plants have mechanisms to protect themselves and harbor various defense (secondary) metabolites, which may be present constitutively or accumulated (induced) after pest attack, and exert antibiotic or antixenotic effects on the attacking organism (Mithöfer and Boland 2012; Kessler 2015). Correct recognition of an intruder and timely accumulation of defense compounds are crucial to induced resistance, whereas biosynthesis of constitutive defense compounds, which are always present, may consume

${ }^{\dagger}$ Corresponding author: J. R. Paudel: E-mail: jamuna.paudel@agr.gc.ca

*The $\boldsymbol{e}$-Xtra logo stands for "electronic extra" and indicates that five supplementary tables are published online.

This article is in the public domain and not copyrightable. It may be freely reprinted with customary crediting of the source. The American Phytopathological Society, 2017. resources from the plant even in the absence of pest or pathogen attack (Mithöfer and Boland 2012). The associated cost of production of secondary metabolites can be offset by balancing primary metabolism with resource turnover and remobilization (Neilson et al. 2013). Among the wide variety of secondary metabolites produced in plants, the majority have unknown function. Steroidal glycoalkaloids (SGAs) are major constitutively produced secondary metabolites in the members of Solanaceae and Liliaceae families (Friedman 2006; Munafo and Gianfagna 2015; Van Gelder et al. 1988). SGAs $\alpha$-solanine and $\alpha$-chaconine (Fig. 1A) constitute about $95 \%$ of total glycoalkaloids in the cultivated potato Solanum tuberosum. These metabolites exhibit antimicrobial properties and disrupt cellular membrane integrity by binding to sterols in fungal membranes (Keukens et al. 1995; Morrissey and Osbourn 1999; Nema et al. 2008; Roddick and Rijnenberg 1986). They inhibit acetylcholinesterase activity in neurons and function as antifeedants in insect pests (Hollister et al. 2001; Roddick 1989; Tingey 1984; Wierenga and Hollingworth 1992). High levels of SGAs can cause gastrointestinal disorders and are associated with neurotoxic and teratogenic effects in animals (Friedman and Levin 2016; Friedman et al. 1991). As a result, SGAs in potato for human consumption are under health regulatory control, with levels limited to less than $200 \mathrm{mg}$ per kilogram of tuber (Dolan et al. 2010). Reducing SGA levels, therefore, is an important potato breeding target (Aharoni and Itkin 2016; Sawai et al. 2014; Van Gelder et al. 1988).

The SGA biosynthetic pathway in plants can be divided into two parts: i) synthesis of a nitrogenous aglycone and ii) glycosylation of the aglycone (Cárdenas et al. 2015). The complete pathway has not yet been elucidated, but multiple steps have been discovered and most pathway genes have likely been cloned to date (Cárdenas et al. 2016; Itkin et al. 2011, 2013; McCue et al. 2007; Sawai et al. 2014). Cholesterol is the precursor for synthesis of SGAs, when a series of enzymatic reactions, including oxidation, hydroxylation, and transamination, lead to synthesis of a nitrogenous aglycone. Recently, Itkin et al. (2013) have identified GLYCOALKALOID METABOLISM 4 (GAME4), a cytochrome P450 enzyme required for glycoalkaloid biosynthesis, which is active at the bifurcation step for the synthesis of nitrogenous SGAs and non-nitrogenous steroidal saponins. Downregulation of GAME4 expression resulted in altered metabolic profiles in tomato and potato, including reduction of the SGA levels. Downregulating GAME4 can be a strategy for SGA reduction; however, the consequences for plant defense are unknown.

Potato is a preferred host to many destructive pests and pathogens, including Colorado potato beetle (CPB), Verticillium 
dahliae, and Phytophthora infestans (El-Bebany et al. 2013; Henriquez et al. 2012; Sablon et al. 2012). In addition, abiotic factors, such as drought, cause significant yield loss and render optimum crop harvest (Obidiegwu et al. 2015). Studies on glycoalkaloids in relation to plant resistance against insects and diseases have shown varied outcomes (Altesor et al. 2014; Friedman 2002; Milner et al. 2011; Sablon et al. 2012). $\alpha$ Tomatine was shown to inhibit mycelial growth in a wide range of fungal species, such as Colletotrichum orbiculare, Septoria linicola, and Helminthosporium turcicum (Arneson and Durbin 1968). The same SGA inhibited zoospore germination of the oomycete $P$. infestans, yet surprisingly, stimulated mycelial growth (Mustafa and Dyakov 1991). Potato glycoalkaloids $\alpha$-solanine and $\alpha$-chaconine inhibited spore formation and fungal growth in liquid culture (Fewell and Roddick 1997). Other studies found no relationship between total glycoalkaloids (TGAs) and resistance to fungal diseases in potato (Andrivon et al. 2003; Frank et al. 1975). On the contrary, potato tubers with high levels of TGA were more susceptible to bacterial scab (Frank et al. 1975). $\mathrm{CPB}$, a specialist on the Solanaceae plant family, is a gregarious defoliator; both adults and larvae feeding on leaves can defoliate an entire field (Hare 1980; Sablon et al. 2012). SGA effects on CPB are dependent on the specific glycoalkaloid compound. For example, wild Solanum species related to potato harbor glycoalkaloids containing tetraose sugar molecules, which were correlated with increased resistance to $\mathrm{CPB}$, whereas potato that harbors high levels of triose glycoalkaloids $\alpha$-solanine and $\alpha$-chaconine is susceptible (Hollister et al. 2001; Pelletier et al. 2013; Sinden et al. 1986; Tai et al. 2014). On the other hand, leptinines and leptines, which are the hydroxylated and $O$-acetylated forms of $\alpha$-solanine and $\alpha$-chaconine, respectively, present in S. chacocense deter CPB feeding (Cooper et al. 2007; Mweeta et al. 2012). These metabolites caused slow development, inhibited weight gain, and increased larval mortality of CPB (Lorenzen et al. 2001). Although glycoalkaloids are a major secondary metabolite in potato, their role in interactions with major pathogens and pest has not been well-studied.

In this study, plant defense responses against insect pest $\mathrm{CPB}$, potato pathogen $V$. dahliae, and drought (osmotic) stress were compared in GAME4 RNA interference (RNAi) lines and wild type (WT) to investigate the role of the SGAs in potato.

\section{RESULTS}

Metabolite profile in $G A M E 4$ knockdown lines.

Itkin et al. (2013) have shown that knockdown of GAME4 decreases SGA levels in potato and tomato. We used the same RNAi vector to transform $S$. tuberosum 'Bintje'. Genomic polymerase chain reaction (PCR) was used to confirm insertion of the RNAi vector. A total of six transgenic lines were generated. The selection of transgenic lines for further analysis was based on two factors: i) Levels of GAME4 transcripts are less than $50 \%$ of WT and ii) GAME4 RNAi lines have decreased levels of SGAs. There were only two clones fitting these criteria, T8 and T9. Table 1 shows the GAME4 transcript levels in the GAME4 RNAi lines compared with the mock-transformed WT control 'Bintje'. GAME4 RNAi lines T8 and T9 have $44.2 \%$ and $25.5 \%$ of the expression of GAME4 gene as compared with $100 \%$ in WT potato. The features list obtained from the untargeted metabolite analysis data processing is included in Supplementary Table S1. Supplementary Table S2 contains putative metabolites exhibiting decreased levels in both GAME4 knockdown lines T8 and T9 and those decreased in either T8 or T9 compared with WT $(P \leq 0.05)$. Features identified as steroidal glycoalkaloids are listed in Table 2. The level of feature 852.52/8.2, identified as $\alpha$-chaconine, was significantly reduced in both the GAME4 knockdown lines compared with WT (Fig. 2). Feature 706.43/8.1, identified as $\beta$-chaconine, was also decreased in T9 (Table 2). The peak intensity of feature $868.5054 / 8.2$, identified as $\alpha$-solanine, was decreased in T8 and T9 compared with WT; however, the $t$ test indicated significant reduction in T8 only at $P \leq 0.05$ (Fig. 2 ). Feature $868.5054 / 8.2$ also matches to solamargine and $\beta$-solamarine, which are the glycoalkaloids with solasodine and dehydrotomatidine aglycone, respectively, with chacotriose carbohydrate moiety linked to them. However, these metabolites are mostly reported in other solanaceous plants, such as S. dulcamara and S. nigrum (Sun and Sneng 1998). Other features identified as glycoalkaloids showed differences between GAME4 RNAi lines and WT. The level of feature 400.3576/8.1 was increased in both T8 and T9 and was identified as demissidine, spirosolane skeleton, or 3-epidemissidine. Features identified as dehydrotomatine (1032.5277/8.1) and lycoperoside D ( $\gamma$-tomatine, $740.4451 / 8.1)$ were increased in T8 only.

It was observed that knockdown of the GAME4 gene results in an alteration of metabolic flux. The levels of the majority of features showing differences with WT were increased in the knockdown lines and were similar between T8 and T9. The

Table 1. Relative transcript abundance of GAME4 in different potato lines

\begin{tabular}{lcc}
\hline Line $^{\mathbf{a}}$ & Relative gene expression $(\boldsymbol{G A M E 4 / E F - 1 \alpha})$ & \% 'Bintje' \\
\hline WT & $0.183 \pm 0.008$ & 100 \\
T9 & $0.047 \pm 0.002$ & 25.5 \\
T8 & $0.081 \pm 0.010$ & 44.2 \\
\hline
\end{tabular}

${ }^{\mathrm{a}} \mathrm{WT}$ is a wild type and T8 and T9 are GAME4 RNAi lines.

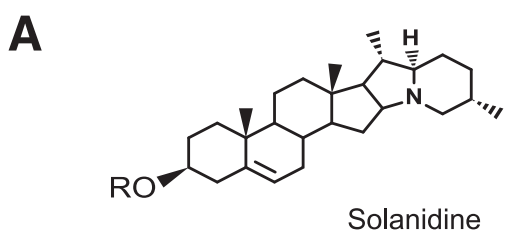

Solanidine

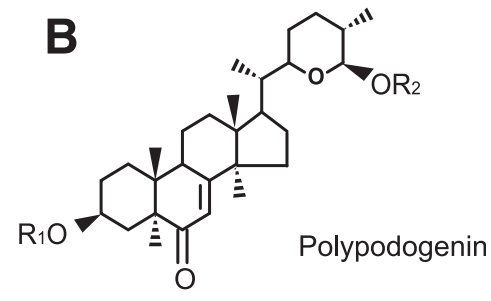

$\mathrm{R}$

Fig. 1. Aglycones with their respective sugar molecules. A, Solanidine forming $\alpha$-chaconine and $\alpha$-solanine. B, Polypodogenin forming polypodoside A and polypodoside $\mathrm{B}$. 
features increased in both the knockdown lines are listed in Supplementary Table S3. Some features had differences between WT and only one of the GAME4 RNAi lines (Supplementary Table S4). Many different classes of compounds were found to be changed in GAME4 RNAi plants. Levels of steroidal saponins were found to be increased in both of the GAME4 RNAi lines. Features matching steroidal saponins are listed in Table 3. The levels of feature 537.3011/14.8 was increased in both of the knockdown lines compared with WT, while all other saponin (1047.5398/8.2, 1047.5395/8.0, 885.4997/8.0, 869.5004/8.1, $739.4299 / 8.0)$ levels were increased in line T8 only. Among these steroidal saponins, features 537.3011/14.8, 885.4997/8.0, and $739.4299 / 8.0$ are also categorized as phytoecdysteroids (Table 4) (Lafont et al. 2002). Polypodoside A (885.4997/8.0) and polypodoside B (739.4299/8.0) are the ecdysteroid glycosides present in Polypodium glycyrrhiza that impart sweet taste to the fern rhizome (Kim and Kinghorn 1989; Kim et al. 1988). Feature 537.3011/14 matches eight different kinds of ecdysteroids (Table 4). Levels of several features broadly classified as alkaloids (492.1881/6.6, 476.1980/6.7, 314.1420/6.5, $309.1222 / 8.1,307.1774 / 4.8$ ) were increased in both T8 and T9, while the level of feature 276.1246/8.1, which was matching alkaloids dubinidine and ribaline, was increased in T9 only.

Levels of numerous features (387.2049/5.7, 369.1187/6.1, 317.2019/8.6, 247.1371/10.6, 217.1576, and 209.1562/5.6) increased in both GAME4 RNAi lines were identified as mono-, sesqui-, or di-terpenoids. Few features identified as terpenoids had different levels in T8 and T9. For example, levels of features 509.2361/9.5 and 203.5693/1.7 were increased in T8 only and levels of feature $213.1260 / 6.3$ were increased in T9 only. Features $311.1830 / 8.2$ and 263.1257/13.1 were sesquiterpenoids, and their levels were reduced in both knockdown lines. Feature 213.1480/10.1 was assigned to several octadecanoids, and its level was also found to be reduced in both GAME4 RNAi lines. Several features showing differences with GAME4 RNAi lines and WT were assigned to flavonoids. Flavonoid features 723.2226/1.7, 465.1074/6.4, and 303.0496/6.4 had levels increased in both knockdown lines compared with WT. Levels of other features assigned as flavonoids, coumarin (247.1012/4.6) and hydroxycoumarin (163.0392/5.9 and 163.0394/4.4), were also increased in both GAME4 RNAi lines. Feature 611.1347/6.3 was classified as a flavonoid glycoside and its levels decreased in T8 only, while features 335.0872/1.8 and 239.0947/8.2, identified as sophoracoumestan A (coumestan flavonoid) and coumaric acid derivatives, respectively, were increased in T9 only.

Other differences include increased levels, in T9 only, of features $855.7157 / 8.1$ and 562.4265/8.1, which were classified as sterol lipid and sphingolipid, respectively.

\section{Development of CPB is affected in GAME4 RNAi lines.}

Newly hatched CPB L1 larvae were restricted to feeding on WT and GAME4 RNAi foliage from emergence to adult stage, in order to investigate the role of SGAs on CPB growth and development. The number of days each surviving insect took to reach to L2, L3, L4, pupation, and adult stage was studied in

Table 2. Features assigned as steroidal glycoalkloids and their intensity in different lines of potato

\begin{tabular}{|c|c|c|c|c|c|c|c|c|}
\hline \multirow[b]{2}{*}{ Feature } & \multirow[b]{2}{*}{ Theoretical mass } & \multirow[b]{2}{*}{$\Delta$ ppm } & \multirow[b]{2}{*}{ Glycoalkaloid } & \multirow[b]{2}{*}{ Chemical formula } & \multicolumn{3}{|c|}{ Peak intensity $^{a}$} & \multirow[b]{2}{*}{ Remarks } \\
\hline & & & & & WT & T8 & T9 & \\
\hline $852.5254 / 8.2$ & 851.5031 & 17 & $\alpha$-chaconine & $\mathrm{C} 45 \mathrm{H} 73 \mathrm{NO} 14$ & 2.82 & 2.53 & 2.55 & $\begin{array}{l}\text { Decreased in both } \mathrm{T} 8 \text { and } \mathrm{T} 9 \\
\text { compared with control }\end{array}$ \\
\hline $868.5054 / 8.2$ & 867.498 & 0 & $\begin{array}{l}\text { solamargine } \\
\alpha \text {-solanine } \\
\beta \text {-solamarine }\end{array}$ & $\mathrm{C} 45 \mathrm{H} 73 \mathrm{NO} 15$ & 2.78 & 2.53 & 2.63 & Decreased in $\mathrm{T} 8$ \\
\hline $706.4391 / 8.1$ & 705.4452 & 18 & $\beta$-chaconine & C39H63NO10 & 3.13 & 3.03 & 2.72 & Decreased in $\mathrm{T} 9$ \\
\hline $1032.5277 / 8.1$ & $1,031.53$ & 9 & dehydrotomatine & $\mathrm{C} 50 \mathrm{H} 81 \mathrm{NO} 21$ & 1.11 & 2.78 & 0.99 & Increased in $\mathrm{T} 8$ \\
\hline $740.4451 / 8.1$ & 739.4507 & 17 & lycoperoside D & C39H65NO12 & 0.92 & 2.24 & 0.85 & Increased in $\mathrm{T} 8$ \\
\hline $400.3576 / 8.1$ & 399.3501 & 0 & $\begin{array}{l}\text { demissidine } \\
\text { spirosolane skeleton } \\
\text { 3-epidemissidine }\end{array}$ & $\begin{array}{l}\mathrm{C} 27 \mathrm{H} 45 \mathrm{NO} \\
\mathrm{C} 27 \mathrm{H} 45 \mathrm{NO} \\
\mathrm{C} 27 \mathrm{H} 45 \mathrm{NO}\end{array}$ & 1.99 & 1.76 & 2.15 & Increased in both $\mathrm{T} 8$ and $\mathrm{T} 9$ \\
\hline
\end{tabular}

${ }^{a}$ Average $\log _{10}$ value. WT is a wild type and T8 and T9 are GAME4 RNAi lines.

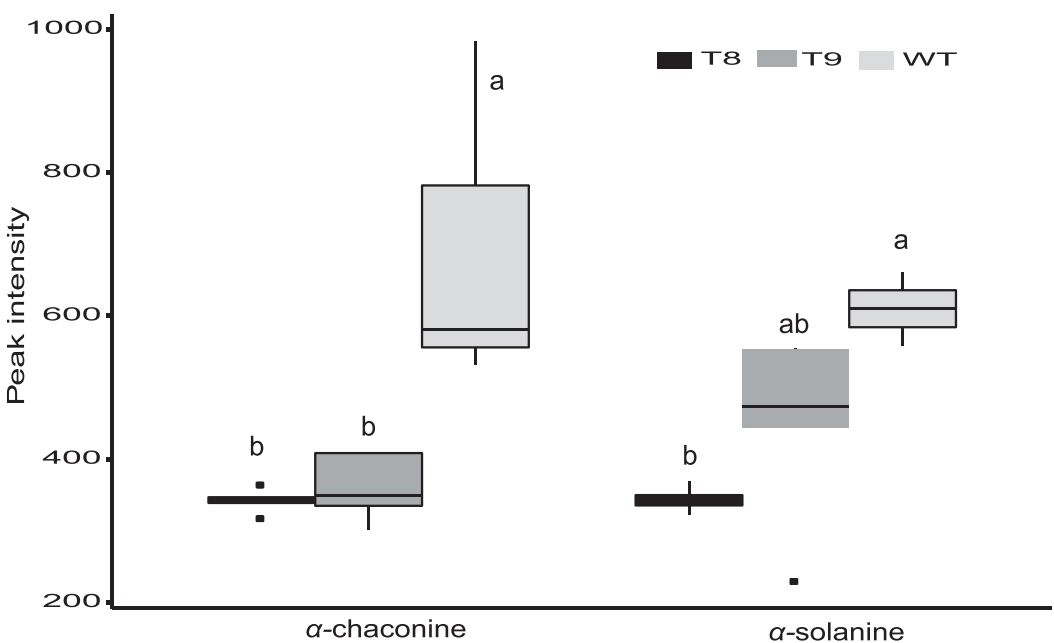

Fig. 2. Levels of $\alpha$-chaconine and $\alpha$-solanine in different lines of potato. Box and whiskers plot of peak intensity for $\alpha$-chaconine (left) and $\alpha$-solanine (right) for the T8 (black), T9 (dark gray), and wild type (WT) (light gray). Different letters indicate significant difference at $P \leq 0.05$. 
WT and GAME4 knockdown potato. CPB developed uniformly across all the lines until L4 stage and reached L2, L3, and L4 stages in $2.02 \pm 0.19,4.21 \pm 0.62$, and $7.07 \pm 1.25$ days, respectively, after egg hatch. This time period is within the normal range described for CPB development in potato (Alyokhin 2008). However, the number of days CPB needed to develop through pupal and adult stage is significantly different $(P \leq$ 0.05 ) between WT and GAME4 knockdown plants. CPB reached pupal stage in $15 \pm 0.5$ and $16.67 \pm 0.93$ days while feeding on lines T8 and T9, respectively, whereas insects needed $19.86 \pm$ 1.28 days on the WT plants. Adults emerged after $21.33 \pm 0.67$, $21.89 \pm 0.56$, and $25 \pm 1.28$ days on T8, T9, and WT plants, respectively.

The weight of the individual insects and their developmental stages during the entire experiment is shown in Figure 3A. No significant difference in insect weight and leaf consumption was seen while feeding on WT and GAME4 RNAi plants (data not shown). On day 13, when all the surviving insects had passed L3 stage, the survival analysis shows that insects feeding on lines T8 and T9 have more L1 to L3 deaths compared with WT (Fig. 3B). CPB feeding on WT leaves died at later stages so that, by the end of the experiment, the numbers of insects that survived feeding on T8, T9, and WT leaves were similar.

\section{Verticillium infection in GAME4 knockdown lines.}

Verticillium pathogens that enter the plant through root surfaces and colonize xylem vessels block water movement and cause wilting and senescence of the infected plants (Fradin and Thomma 2006). Quantitation of fungal colonization was done in V. dahliae-inoculated WT and GAME4 knockdown plants. Quantitative (q)PCR-based analysis indicated the presence of significantly higher copy numbers of $V$. dahliae in inoculated stems and roots of GAME4 RNAi line T8 as compared with WT 'Bintje' (Fig. 4A and B). Unlike T8, no difference in $V$. dahliae colonization between $\mathrm{T} 9$ and $\mathrm{WT}$ infected plants was observed. In addition, we found no significant difference between the infected and noninfected WT plants, indicating that 'Bintje' bears some resistance to the pathogen.
Therefore, by disrupting the SGA biosynthetic pathway in T8, plant resistance to Verticillium pathogens was compromised. However, this disruption in T9 did not result in compromised resistance. Examination of the differences in metabolites between T8 and WT and T8 and T9 provide some insight into interactions between $V$. dahliae and potato. T8 lines were reduced in both $\alpha$-solanine and $\alpha$-chaconine, whereas T9 lines had significantly reduced $\alpha$-chaconine but not $\alpha$-solanine. The remaining SGA levels in T9 may have contributed to preventing colonization by $V$. dahliae. Additionally, T9 but not T8 showed increases in the phenolic compounds coumestan flavonoid and coumaric acid derivatives. Further studies are needed to examine plant metabolite interaction with $V$. dahliae.

\section{Drought stress response.}

All the tested parameters of drought stress created by osmotic potential - plant height, root length, root and shoot fresh and dry weight, leaf area and leaf numbers-were reduced in drought-stressed plants compared with non-stressed plants in WT as well as both GAME4 RNAi lines. Therefore, comparison of relative ratios (ratio of drought stressed to non-stressed plants) of each parameter across the potato lines was done, and no significant differences between GAME4 knockdown and WT plants were observed (data not shown).

\section{DISCUSSION}

The role of SGA biosynthesis in plant defense against biotic and abiotic stress was examined in this study. We used RNAi to diminish expression of the GAME4 gene that encodes a key enzyme in the SGA biosynthetic pathway. Comparison of metabolites between potato lines showed that levels of glycoalkaloids $\alpha$-solanine and $\alpha$-chaconine were reduced in GAME4 RNAi lines. Additionally, interference within GAME4 expression led to increased levels of non-nitrogenous saponins. These results were observed in both the T8 and T9 lines and in three other lines (data not shown). Our results corroborate previous findings by Itkin et al. (2013) and support the function of

Table 3. Features assigned as steroidal saponins and their intensity in different lines of potato

\begin{tabular}{|c|c|c|c|c|c|c|c|}
\hline \multirow[b]{2}{*}{ Feature } & \multirow[b]{2}{*}{ Theoretical mass } & \multirow[b]{2}{*}{$\Delta$ ppm } & \multirow[b]{2}{*}{ Formula } & \multicolumn{3}{|c|}{ Peak intensity $^{a}$} & \multirow[b]{2}{*}{ Remarks } \\
\hline & & & & WT & T8 & T9 & \\
\hline $869.5004 / 8.1$ & 868.482 & 12 & $\mathrm{C} 45 \mathrm{H} 72 \mathrm{O} 16$ & 2.96 & 2.74 & 2.81 & Decreased in $\mathrm{T} 8$ \\
\hline $537.3011 / 14.8$ & 536.2985 & 8 & $\mathrm{C} 29 \mathrm{H} 44 \mathrm{O} 9$ & 2.27 & 2.65 & 2.57 & Increased in $\mathrm{T} 8$ and $\mathrm{T} 9$ \\
\hline $1047.5398 / 8.2$ & $1,046.53$ & 2 & $\mathrm{C} 51 \mathrm{H} 82 \mathrm{O} 22$ & 0.91 & 2.65 & 1.39 & Increased in $\mathrm{T} 8$ \\
\hline $1047.5395 / 8.0$ & $1,046.53$ & 2 & $\mathrm{C} 51 \mathrm{H} 82 \mathrm{O} 22$ & 1.16 & 2.58 & 1.42 & Increased in $\mathrm{T} 8$ \\
\hline $885.4997 / 8.0$ & 884.477 & 17 & $\mathrm{C} 45 \mathrm{H} 72 \mathrm{O} 17$ & 1.02 & 2.39 & 0.94 & Increased in $\mathrm{T} 8$ \\
\hline $739.4299 / 8.0$ & 738.419 & 4 & С39H62O13 & 1.11 & 2.69 & 1.05 & Increased in $\mathrm{T} 8$ \\
\hline
\end{tabular}

a Average $\log _{10}$ value. WT is a wild type and T8 and T9 are GAME4 RNAi lines.

Table 4. Features with ecdysteroid-specific backbone and their intensity in different lines of potato

\begin{tabular}{|c|c|c|c|c|c|c|c|c|}
\hline \multirow[b]{2}{*}{ Feature } & \multirow{2}{*}{$\begin{array}{c}\text { Theoretical } \\
\text { mass }\end{array}$} & \multirow[b]{2}{*}{$\Delta p p m$} & \multirow[b]{2}{*}{ Phytoecdysteroid } & \multirow{2}{*}{$\begin{array}{l}\text { Chemical } \\
\text { formula }\end{array}$} & \multicolumn{3}{|c|}{ Peak intensity $^{a}$} & \multirow[b]{2}{*}{ Remarks } \\
\hline & & & & & WT & T8 & T9 & \\
\hline $885.4997 / 80$ & 884.4769 & 16 & Polypodoside A & $\mathrm{C} 45 \mathrm{H} 72 \mathrm{O} 17$ & 1.02 & 2.39 & 0.9 & Increased in $\mathrm{T} 8$ \\
\hline $739.4299 / 8.0$ & 738.4190 & 4 & Polypodoside B & С39H62O13 & 1.11 & 2.69 & 1.06 & Increased in T8 \\
\hline $537.3011 / 14.8$ & 536.2985 & 9 & $\begin{array}{l}\text { 5,29-Dihydroxycapitasterone } \\
\text { 28-Epi-sengosterone } \\
\text { 24- Hydroxycyasterone } \\
\text { 23-Hydroxycyasterone } \\
\text { 24-Hydroxy-24,28 dihydrocarthamosterone } \\
\text { Reptanslactone B } \\
\text { Rhapontisterone R1 } \\
\text { Sengosterone }\end{array}$ & $\mathrm{C} 29 \mathrm{H} 44 \mathrm{O} 9$ & 2.27 & 2.65 & 2.57 & Increased in $\mathrm{T} 8$ and $\mathrm{T} 9$ \\
\hline
\end{tabular}

\footnotetext{
${ }^{a}$ Average $\log _{10}$ value. WT is a wild type and T8 and T9 are GAME4 RNAi lines.
} 
GAME4 in catalyzing reaction at the bifurcation step to synthesize nitrogenous SGAs and non-nitrogenous saponins. By knocking down SGA biosynthesis, we also observed increases in several other classes of metabolites in GAME4 RNAi lines, including phenolics, terpernoids, and alkaloids, indicating altering of the metabolic flux to other biosynthetic pathways.

The majority of metabolite differences between GAME4 RNAi lines and WT were the same for the two lines T8 and T9.

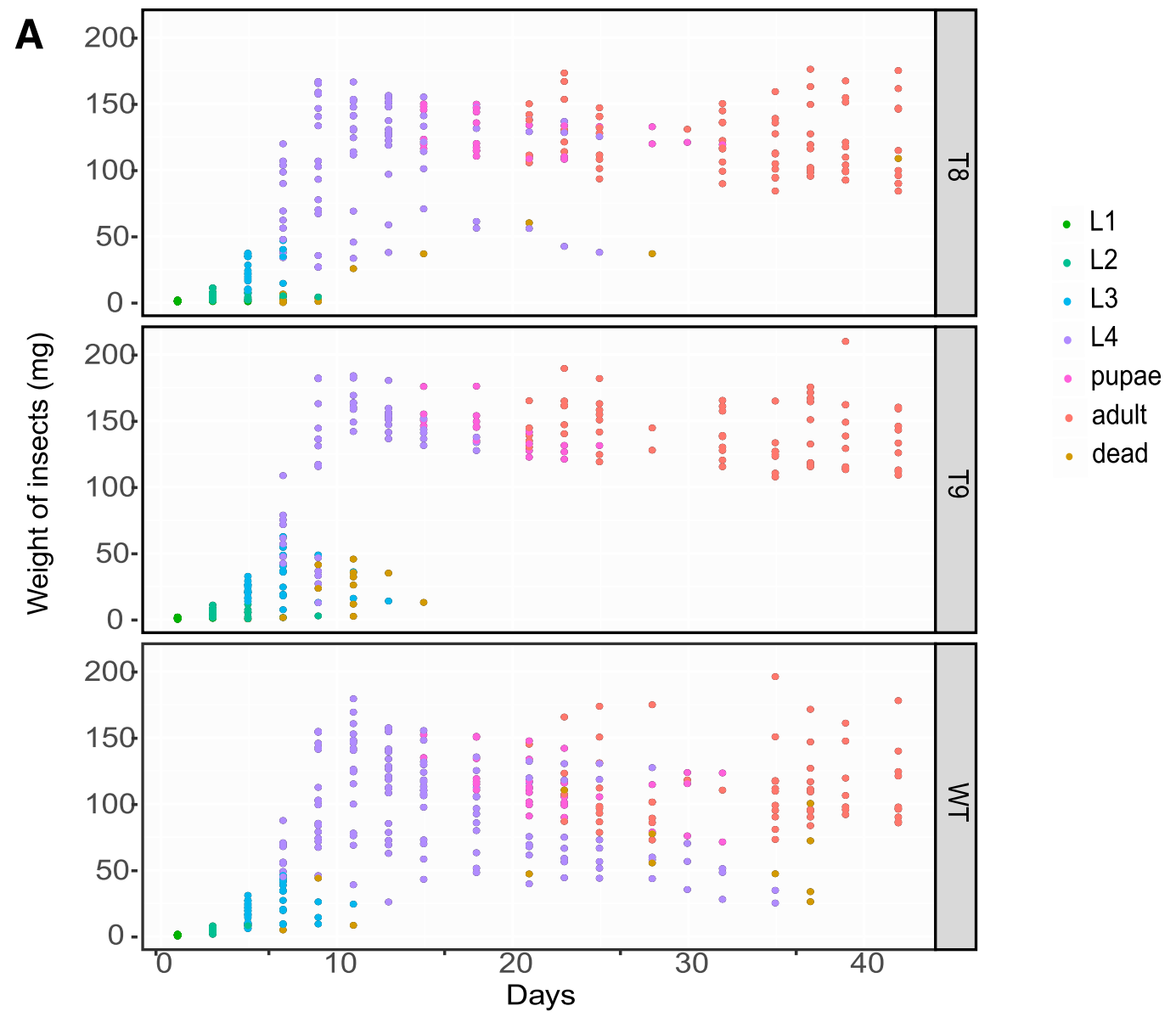

B

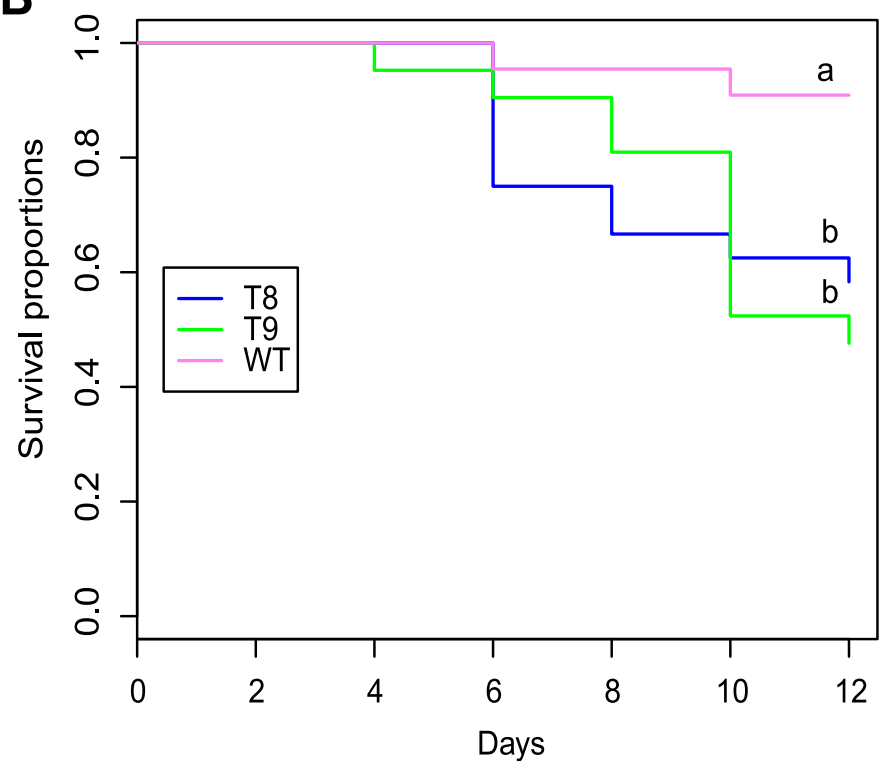

Fig. 3. Growth, development, and survival of Colorado potato beetle Leptinotarsa decemlineata on different lines of potato. A, Weight of individual insect in milligrams during the entire feeding experiment is plotted and color coded for all stages of development, L1 (light green), L2 (dark green), L3 (blue), L4 (purple), pupae (pink), adult (red, and dead (brown) in T8, T9, and wild type (WT) lines. B, Kaplan-Meier survival curve showing proportion of insects that survived and passed L3 stage on T8 (blue), T9 (green), and WT (pink) plants after 12 days of the experiment. Different letters indicate significant differences between lines at $P \leq 0.05$. 
Nevertheless, there were differences between the lines that can be attributed to differences in the knockdown levels of GAME4 expression. T8 and T9 also likely have differences in insertion sites of the RNAi T-DNA in the genomic DNA, which can also contribute to differences between the lines (i.e., position effect).

The decreased SGA content in GAME4 RNAi plants were more compatible for human consumption. However, the altered metabolite profiles in GAME4 RNAi plants also affected potato interaction with pathogen and pest defense responses. Numerous SGAs present in Solanaceae plants have been reported to deter insect pests (Sinden et al. 1986; Tingey 1984). However, this had not been noted for $\alpha$-solanine and $\alpha$-chaconine. On the contrary, studies on a wild Solanum relative of potato with CPB resistance indicated that one property they shared in common was low levels of $\alpha$-solanine and $\alpha$-chaconine (Tai et al. 2015). Other studies showed that artificial diets for CPB required inclusion of potato foliage and that inclusion of some $\alpha$-solanine and $\alpha$-chaconine could improve weight gain (Kowalski et al. 1999). The effect of disrupting the SGA pathway on insect growth and development were examined in this study. The amount of leaf consumed by CPB and weight gain for insects feeding on leaves of the two GAME4 RNAi lines were similar to that of WT in the current study. These results are consistent with natural selection of CPB to tolerate high levels of $\alpha$-solanine and $\alpha$-chaconine in potato and indicate that $\mathrm{CPB}$ may have developed mechanisms to overcome the toxicity of those SGAs or even use these metabolites for own benefit (Marciniak et al. 2010). In addition to sterol binding, SGA toxicity in animals is also attributed to antiacetylcholinesterase (AChE) activity that interferes with the function of neurons (Friedman 2004; Roddick 1989). Indeed, many insecticides, such as carbamates and organophosphates, are known to block AChE that lead to neural disturbance and death of the pest (Alyokhin et al. 2008). However, it was found that $\mathrm{CPB}$ AChE was significantly less inhibited by $\alpha$-chaconine compared with $\mathrm{AChE}$ in other organisms (Wierenga and Hollingworth 1992). These studies point to a mechanism for CPB adaptation to high $\alpha$-solanine and $\alpha$-chaconine. The observed early instar larval death of CPB while feeding on GAME4 knockdown lines could also be due to increased level of saponins, as suggested by Itkin et al. (2013). Steroidal saponins have insecticidal activity and their presence in various plant families is correlated with increased resistance against insect pests (De Geyter et al. 2007; Nielsen et al. 2010). CPB larvae fed on potato foliage dipped in saponin extracts from alfalfa and other Medicago species reduced food intake and the growth rate and insect survival were affected (De Geyter et al. 2007; Szczepanik et al. 2004).

Our results also showed that CPB developed earlier on lines T8 and T9 compared with WT. Insect development is triggered by the molting hormone ecdysone and 20-hydroxyecdysone (Gäde et al. 1997). These hormones are part of a family of ecdysteroids initially identified as hormonal compounds in insect that have an important role during ecdysis and metamorphosis of the arthropods but also is found in other organisms (Spindler et al. 2009). Plants harbor phytoecdysteroids, which can have a role to protect plants from various predators by disrupting their endocrine systems (Dinan et al. 2009; Maria et al. 2005). Various phytoecdysteroids are shown to be agonists of the insect molting hormones (Adler and Grebenok 1995; Savchenko et al. 2000). Phytoecdysteroids are mostly derived from cholesterol but, in some plants, they were shown to be produced from other sterols also, such as lathosterol in Spinacia oleraceae (Dinan et al. 2009; Grebenok and Adler 1993). More than 400 different kinds of phytoecdysteroids have been identified in various plants, fungi, and aquatic species, and the characteristic features of ecdysteroids are the presence of a cis $(5 \beta-\mathrm{H})$ junction of rings $\mathrm{A}$ and $\mathrm{B}$, a 7-ene-6-one chromophore, and a trans $(14 \alpha-\mathrm{OH}$ or $\mathrm{H})$ junction of rings $\mathrm{C}$ and $\mathrm{D}$ in the sterol backbone (Lafont et al. 2002, 2012). Potato preferentially uses cholesterol for biosynthesis of SGAs, and phytoecdysteroid synthesis in potato has not been described previously (Dinan et al. 2009). However, the presence of ecdysteroid agonist and antagonist activities has been observed in members of the Solanaceae family (Savchenko et al. 2000). The results of this study suggest that decreased SGA biosynthesis in GAME4 RNAi potato may have allowed remobilization of sterols to phytoecdysteroids. Some of the steroidal saponins identified were also classified as phytoecdysteroids. Levels of polypodoside $\mathrm{A}$ and polypodoside $\mathrm{B}$, which are the glycosides of polypodogenin (Fig. 1B), are 25 to 35 times higher in line T8 than in WT (Table 4). Another feature (537.3011/14.8) that matches to number of photecdysteroid glycosides is elevated in
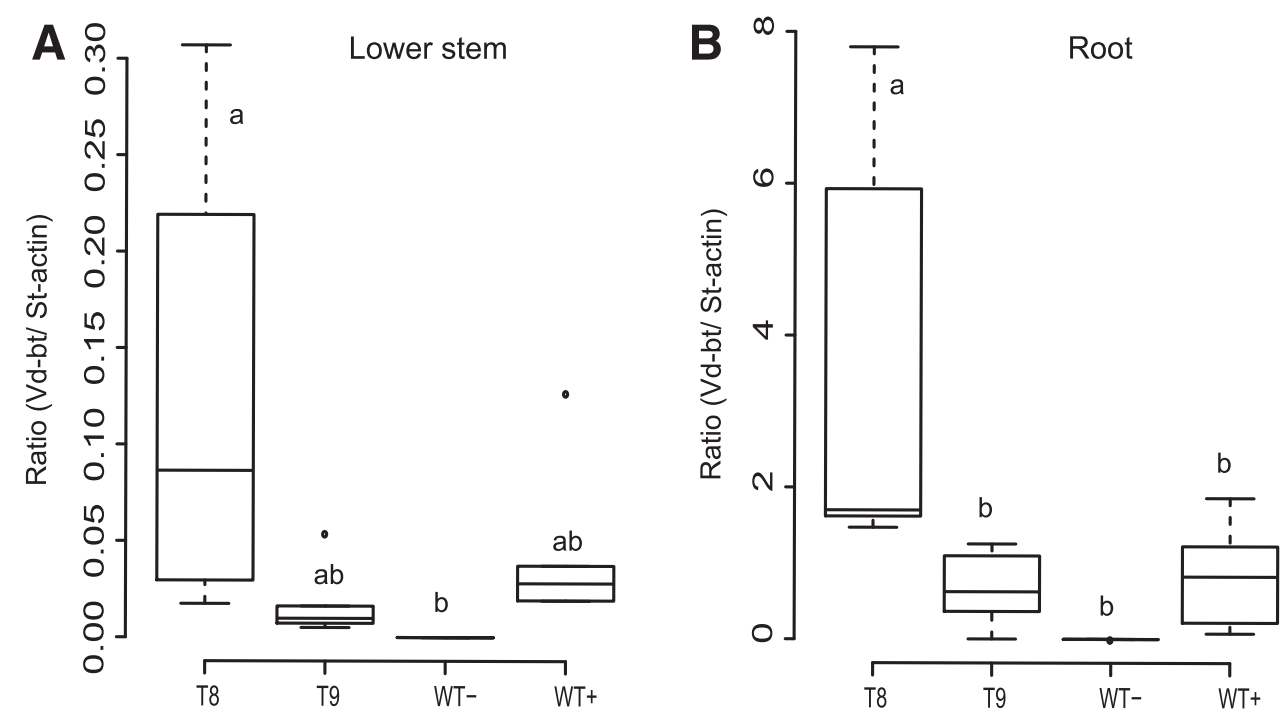

Fig. 4. Levels of Verticillium dahliae colonization in the $\mathbf{A}$, lower stem and $\mathbf{B}$, roots of different potato lines. Boxes and whiskers show ratios of the copy numbers of $V$. dahliae $\beta$-tubulin (Vd-bt) to Solanum tuberosum $\alpha$-actin (St-actin) genes obtained from digital droplet polymerase chain reaction, using extracts from pathogen-infected T8, T9, and wild type (WT+) and noninfected WT (WT-) plant samples. Different letters indicate significant difference between treatments at $P \leq 0.05$. 
both T8 and T9 (Table 4). A significant portion of ecdysteroids in plants remains in the form of glycosides and they are biologically active, although the bulkier structure of glycosides may reduce activation of ecdysteroid receptors in insects (Maria et al. 2005). The results of this study suggest that accelerated larval development of CPB feeding on GAME4 RNAi lines may be attributed to increased phytoecdysteroids.

Glycoalkaloids have antifungal properties and it was shown that potato and tomato SGAs inhibit fungal growth (Fewell and Roddick 1997). When SGAs enter membrane bilayers, aglycones form complexes with membrane sterols, followed by structural rearrangement, leading to membrane disruption (Friedman 2006). Glycoalkaloids can also inhibit ergosterol biosynthesis, which further contributes to its toxicity to fungi (Simons et al. 2006). Our results indicate that metabolite changes induced by blocking SGA biosynthesis affected interaction between potato and $V$. dahliae for the T8 line compared with WT. On the other hand, T9 did not have significantly different levels of the pathogen, compared with WT, in infected plants. The differences may be attributed to position effects of the insertion sites of the RNAi T-DNA in the genomic DNA, which varies between T8 and T9. Also, gene expression and enzyme activities are controlled at levels beyond transcription. Therefore, GAME4 RNAi knockdown of transcript levels is not the single determining factor for levels of GAME4 enzyme activity. The metabolite data indicated that lower levels of $\alpha$-solanine was found in T8; however, this SGA in T9 was not significantly different from WT. Phenolic compounds have been reported to be involved in plant defense against $V$. dahliae (Daayf et al. 2012). T9 was found to have increased levels of metabolites in this class that may have also contributed to increased resistance to $V$. dahliae compared with T8. Further studies will be needed to confirm potato metabolite interactions with $V$. dahliae. In the in vitro system of pathogen quantitation, we did not observe wilting symptoms in the inoculated plants.

The results show that knockdown of GAME4 did not affect drought tolerance. There have been reports of increased SGAs in drought-stressed potato (Bejarano et al. 2000); however, it was not known what role SGAs play in the drought stress response. The results reported here suggest that SGAs do not contribute to drought response created by osmotic potential.

\section{Conclusion.}

The knockdown of GAME4 in this study shows that modulation of the SGA biosynthetic pathway at a single enzyme site leads to wider metabolic changes. The resulting metabolite changes in plants with reduced GAME4 expression affected response of CPB in potato. One of the GAME4 RNAi lines had significant loss of resistance to $V$. dahliae, however the other one did not. Differences in metabolite profiles between the two GAME4 RNAi lines may contribute to differences in response to $V$. dahliae. Further studies will be needed confirm a role for GAME4 in $V$. dahliae resistance. Drought tolerance was not affected by RNAi knockdown of GAME4. These results demonstrate that targeted modification of secondary metabolic pathways in plants can have wide-ranging effects on pest and pathogens.

\section{MATERIALS AND METHODS}

\section{Generation of $G A M E 4$ knockdown lines.}

$G A M E 4$ knockdown lines of potato were generated using the GAME4 RNAi construct created by introducing a GAME4 fragment from tomato into pENTER/D-TOPO (Invitrogen) (Itkin et al. 2013). The construct was transferred to binary vector pK7GWIWG2 (II) using Gateway LR Clonase enzyme II enzyme mix (Invitrogen). These vectors were used for Agrobacteriummediated transformation of S. tuberosum 'Bintje', following a method described by Gustafson et al. (2006). Six GAME4 knockdown lines thus generated were tested for the presence of RNAi constructs. Genomic DNA was isolated and was PCRamplified according to Tai et al. (2007), using primers listed in Supplementary Table S5. Downregulation of GAME4 transcripts were tested using real-time RT-PCR according to Tai et al. (2009). Transcript levels were normalized to levels of the elongation factor 1 a transcript and three biological replicates of each line were included.

\section{Untargeted small metabolite analysis.}

For sample collection and extraction, tissue culture plantlets were transferred to soil in 6-inch pots and were allowed to grow in the greenhouse (16-h day and 8-h night at 20 and $23^{\circ} \mathrm{C}$, respectively) for four weeks. Foliar samples were collected from mature plants by pooling apical leaflets of the third leaf from the top of the plant and were flash-frozen in liquid nitrogen. Three to five biological replicates of each sample were stored at $-80^{\circ} \mathrm{C}$ until extraction.

Frozen samples were ground to fine powder using a chilled mortar and pestle. While keeping samples frozen on cryostation (SPEX Sample prep; Metuchen, NJ, U.S.A.) filled with liquid nitrogen, $100 \mathrm{mg}$ of the ground samples were transferred to 2-ml screw-cap tubes, and metabolites were extracted in $400 \mu \mathrm{l}$ of extraction buffer $(92 \%$ methanol in water and acidified with $0.1 \%$ formic acid). Samples were briefly vortexed for uniform mixing and were kept on ice until all the samples were prepared. Samples were then sonicated in Branson water bath for $20 \mathrm{~min}$ and were centrifuged at $12,000 \times g$ for $10 \mathrm{~min}$. The supernatants were filtered through $0.2-\mu \mathrm{m}$ centrifugal filter units and the filtrates were transferred to liquid chromatographymass spectrometry (LC-MS) auto-sampler vials. Samples were further diluted $10 \times$ to avoid detector saturation and were stored at $-20^{\circ} \mathrm{C}$ until analysis. The samples were equilibrated at $23^{\circ} \mathrm{C}$ in the dark for $1 \mathrm{~h}$ just before analysis and a similar condition was maintained throughout the LC-MS run (Tai et al. 2014).

\section{LC-electrospray ionization-MS.}

For data preprocessing and analysis, the raw file from Waters quadrupole-time-of-flight mass spectrometry was converted to NetCDF, using the data bridge program in MassLynx, and the NetCDF files were imported to MZmine 2 (version 2.11). Data preprocessing and peak picking was accomplished using the following criteria in MZmine. Data were cropped from 1 to $16 \mathrm{~min}$ of the MS run, to avoid column void and washes. Baseline of the total ion chromatogram was created by selecting $\mathrm{m} / \mathrm{z}$ bin width 0.1 and peak detector algorithm within MzMine 2 . Mass peaks were then detected by exact mass detector algorithm in MZmine, with the noise level maintained at $5 \mathrm{ppm}$. A mass chromatogram was built by selecting the following parameters: minimum time span of $0.2 \mathrm{~min}$, minimum peak height at 8 , and $\mathrm{m} / \mathrm{z}$ tolerance of 0.05 or $20 \mathrm{ppm}$. Peaks were then deconvoluted by the algorithm local minimum search and peaks were aligned allowing the $\mathrm{m} / \mathrm{z}$ tolerance of 0.05 or 20 $\mathrm{ppm}$ and retention time (RT) tolerance of $0.5 \mathrm{~min}$. This was followed by gap filling by allowing $\mathrm{m} / \mathrm{z}$ and $\mathrm{RT}$ tolerance of 20 ppm and $0.2 \mathrm{~min}$, respectively; and finally, the obtained mass list with peak heights (intensity) was exported to an Excel file.

Accurate mass $(\mathrm{m} / \mathrm{z})$ of the compounds plus mass of proton $[\mathrm{M}+\mathrm{H}]^{+}$was used to search the MetLin compound mass database (Smith et al., 2005). Compounds that match to each accurate mass within $20 \mathrm{ppm}$ were identified as putative compounds. There were many features that remained unidentified, while few masses matched to more than one compound. Chemical formula of the ecdysteroids listed in the Ecdybase Database online (Lafont et al. 2002) was used to 
calculate the monoisotopic masses of the compounds. These masses were used to categorize the feature list from MS as putative phytoecdysteroids.

\section{Verticillium infection.}

V. dahliae 6883 was used to inoculate GAME4 RNAi and WT 'Bintje' potato plants. For pathogen inoculation, three-weekold tissue culture plantlets were removed from culture tubes along with agar plugs. Agar was removed from roots by gentle crushing of the plugs with sterile forceps and roots were washed in sterile water. The plants were mock- or pathogen-inoculated by submerging their roots in water or $V$. dahliae spore suspension prepared at $5 \times 10^{-6}$ spores per milliliter, respectively, for $20 \mathrm{~min}$. Five biological replicates of pathogen- or mock-inoculated plants of each line were then transferred to sterile media and continued to grow for six weeks. During sample collection, plants were harvested, roots and shoots were weighed separately, shoots were divided into two parts-below and above $5 \mathrm{~cm}$ plant height - and the samples were quickly frozen in liquid nitrogen. DNA was extracted from these samples, using DNeasy plant mini kit (Qiagen) following manufacturer's protocol. Nanodrop (Thermo Fisher Scientific, Waltham, MA, U.S.A.) was used to assess DNA quality and concentration. Digital droplet (dd)-qPCR (QX200; BioRad, Hercules, CA, U.S.A.) using Evagreen Supermix was used to measure copies of $V$. dahliae in the roots and $5-\mathrm{cm}$ shoot samples. Primer pairs described by Atallah et al. (2007) were used to amplify specific regions of $V$. dahliae $\beta$-tubulin and $S$. tuberosum $\alpha$-actin genes. Each ddPCR reaction consisted of 30 and 4 ng DNA for shoot and root samples, respectively, along with $1 \times$ EvaGreen supermix, $250 \mathrm{nM}$ forward primer, $150 \mathrm{nM}$ reverse primer, and 5 units of HindIII restriction enzyme in $20 \mu \mathrm{l}$ of total volume. The following PCR conditions were used: initial enzyme activation at $95^{\circ} \mathrm{C}$ for $5 \mathrm{~min}$, followed by 40 cycles of denaturation at $95^{\circ} \mathrm{C}$ for $30 \mathrm{~s}$, and annealing and extension at $61^{\circ} \mathrm{C}$ for $1 \mathrm{~min}$.

\section{CPB assay.}

CPB eggs were obtained from the rearing colony at the Agriculture and Agri-Food Canada Fredericton Research and Development Centre (former Potato Research Centre). Uniform 10- to 12-egg masses from the colony were transferred to fresh potato leaves placed in petri dishes lined with moist filter paper until eggs hatched. Larvae hatched within $24 \mathrm{~h}$ (early L1s) were used to set up CPB assay. For this experiment, 'Bintje' WT and GAME4 knockdown potato plants were grown in 6-inch pots in the greenhouse for six weeks. Leaflets were collected from these plants during the entire experiment. Single detached leaflets from each plant line were placed in a petri dish lined with moist filter paper and were used for insect feeding at all times. A total of 25 petri dishes were prepared for each line; therefore, $25 \mathrm{~L} 1 \mathrm{~s}$ picked from different egg masses were weighed and were transferred individually to leaflets in petri dishes. These 25 petri dishes, each representing a single biological replicate, were stacked and placed in a growth room maintained at 22 to $24^{\circ} \mathrm{C}$ with long day (16-h day and 8-h night) conditions. Every second day, the developing insects were transferred to a new petri dish with fresh leaf. In the same time, development stage, weight, and amount of leaf consumed by each insect were recorded. Leaf consumption by CPB was measured by scanning every leaf area before and after insect feeding, using imaging software (WinFOLIA; Régent Instruments Inc., Québec, Canada).

\section{Drought resistance.}

Sorbitol (4\%) in agar media was used to create drought stress for tissue culture plants (Albiski et al. 2012). The presence of sorbitol in the growth media increases osmotic potential and, thus, plantlets grown in this medium suffer from water deficit that mimics drought stress. Cuttings from WT 'Bintje' and each of the GAME4 knockdown lines were grown on media with or without sorbitol for six weeks, and five biological replicates were maintained in each treatment. At the end of the experiment, the plantlets were cut on the surface of media and the stem height, leaf numbers, leaf area, root length, and the root and shoot fresh and dry weights were measured.

\section{Statistical analysis.}

Metabolite data were analyzed using Multiple Experiment Viewer (MeV 4.7.4). The mass list along with retention time and peak intensity were exported from MzMine and were rearranged in a Microsoft Excel file before importing to $\mathrm{MeV}$. Each mass with respective RT was designated as an individual feature. The data were $\log _{10}$-transformed after adding $1 \times 10^{-12}$ to all data to remove zeroes. Analysis of variance (ANOVA) was done using $\log _{10}$-transformed peak intensity to identify features that are significantly different $(P \leq 0.05)$ between lines.

Statistical packages in R (R Core Team 2016) were used to perform ANOVA in pathogen infections and CPB assays. The Kaplan-Meier test is a nonparametric test to estimate the survival probability of a subject as a function of time (Kaplan and Meier 1958). Survival analysis of CPB feeding on GAME4 RNAi lines and WT 'Bintje' was done, and the comparison of Kaplan-Meier survival curves between the different potato lines was performed using the survival package in $\mathrm{R}$ (online). Test parameters of the drought stress experiment were calculated as relative ratios of drought-stressed to nonstressed plants for each line and ANOVA was used to compare these ratios across potato lines.

\section{ACKNOWLEDGMENTS}

We thank L. Campbell for running MS and collecting metabolomics data, M. Shukla for help during the CPB assay, and L. Nolan for technical support.

\section{LITERATURE CITED}

Adler, J. H., and Grebenok, R. J. 1995. Biosynthesis and distribution of insect-molting hormones in plants-A review. Lipids 30:257-262.

Aharoni, A., and Itkin, M. 2016. Plant with altered content of steroidal glycoalkaloids. U.S. Patent 20,160,122,775.

Albiski, F., Najla, S., Sanoubar, R., Alkabani, N., and Murshed, R. 2012. In vitro screening of potato lines for drought tolerance. Physiol. Mol. Biol. Plants 18:315-321.

Altesor, P., García, Á., Font, E., Rodríguez-Haralambides, A., Vilaró, F., Oesterheld, M., Soler, R., and González, A. 2014. Glycoalkaloids of wild and cultivated Solanum: Effects on specialist and generalist insect herbivores. J. Chem. Ecol. 40:599-608.

Alyokhin, A., Baker, M., Mota-Sanchez, D., Dively, G., and Grafius, E. 2008. Colorado potato beetle resistance to insecticides. Am. J. Potato Res. 85:395-413.

Andrivon, D., Corbière, R., Lucas, J. M., Pasco, C., Gravoueille, J. M., Pellé, R., Dantec, J. P., and Ellissèche, D. 2003. Resistance to late blight and soft rot in six potato progenies and glycoalkaloid contents in the tubers. Am. J. Potato Res. 80:125-134.

Arneson, P., and Durbin, R. D. 1968. Studies on the mode of action of tomatine as a fungitoxic agent. Plant Physiol. 43:683-686.

Atallah, Z. K., Bae, J., Jansky, S. H., Rouse, D. I., and Stevenson, W. R. 2007. Multiplex real-time quantitative PCR to detect and quantify Verticillium dahliae colonization in potato lines that differ in response to Verticillium wilt. Phytopathology 97:865-872.

Bejarano, L., Mignolet, E., Devaux, A., Espinola, N., Carrasco, E., and Larondelle, Y. 2000. Glycoalkaloids in potato tubers: The effect of variety and drought stress on the $\alpha$-solanine and $\alpha$-chaconine contents of potatoes. J. Sci. Food Agric. 80:2096-2100.

Cárdenas, P. D., Sonawane, P. D., Heinig, U., Bocobza, S. E., Burdman, S., and Aharoni, A. 2015. The bitter side of the nightshades: Genomics drives discovery in Solanaceae steroidal alkaloid metabolism. Phytochemistry 113:24-32.

Cárdenas, P. D., Sonawane, P. D., Pollier, J., Vanden Bossche, R., Dewangan, V., Weithorn, E., Tal, L., Meir, S., Rogachev, I., Malitsky, 
S., Giri, A. P., Goossens, A., Burdman, S., and Aharoni, A. 2016. GAME9 regulates the biosynthesis of steroidal alkaloids and upstream isoprenoids in the plant mevalonate pathway. Nat. Commun. 7:10654.

Cooper, S. G., Douches, D. S., Coombs, J. J., and Grafius, E. J. 2007 Evaluation of natural and engineered resistance mechanisms in potato against Colorado potato beetle in a no-choice field study. J. Econ. Entomol. 100:573-579.

Daayf, F., El Hadrami, A., El-Bebany, A. F., Henriquez, M. A., Yao, Z., Derksen, H., El-Hadrami, I., and Adam, L. R. 2012. Phenolic compounds in plant defense and pathogen counter-defense mechanisms. Pages 191-208 in: Recent Advances in Polyphenol Research. Wiley-Blackwell, Oxford.

De Geyter, E., Lambert, E., Geelen, D., and Smagghe, G. 2007. Novel advances with plant saponins as natural insecticides to control pest insects. Pest Technol. 1:96-105.

Dinan, L., Harmatha, J., Volodin, V., and Lafont, R. 2009. Phytoecdysteroids: Diversity, biosynthesis and distribution. Pages 3-45 in: Ecdysone: Structures and Functions. Springer, Dordrecht, The Netherlands.

Dolan, L. C., Matulka, R. A., and Burdock, G. A. 2010. Naturally occurring food toxins. Toxins (Basel) 2:2289-2332.

El-Bebany, A. F., Adam, L. R., and Daayf, F. 2013. Differential accumulation of phenolic compounds in potato in response to weakly and highly aggressive isolates of Verticillium dahliae. Can. J. Plant Pathol. 35:232-240.

Fewell, A. M., and Roddick, J. G. 1997. Potato glycoalkaloid impairment of fungal development. Mycol. Res. 101:597-603.

Fradin, E. F., and Thomma, B. P. H. J. 2006. Physiology and molecular aspects of Verticillium wilt diseases caused by $\mathrm{V}$. dahliae and V. alboatrum. Mol. Plant Pathol. 7:71-86.

Frank, J.A., Wilson, J. M., and Webb, .R. E. 1975. The relationship between glycoalkaloids and disease resistance in potatoes. Phytopathology 65 : 1045-1050.

Friedman, J. I. 2004. Cholinergic targets for cognitive enhancement in schizophrenia: Focus on cholinesterase inhibitors and muscarinic agonists. Psychopharmacology (Berl.) 174:45-53.

Friedman, M. 2002. Tomato glycoalkaloids: Role in the plant and in the diet. J. Agric. Food Chem. 50:5751-5780.

Friedman, M. 2006. Potato glycoalkaloids and metabolites: Roles in the plant and in the diet. J. Agric. Food Chem. 54:8655-8681.

Friedman, M., and Levin, C. E. 2016. Glycoalkaloids and calystegine alkaloids in potatoes, Pages 167-194 in: 2nd Ed. Advances in Potato Chemistry and Technology. Elsevier Inc., Amsterdam.

Friedman, M., Rayburn, J. R., and Bantle, J. A. 1991. Developmental toxicology of potato alkaloids in the frog embryo teratogenesis assay-Xenopus (FETAX). Food Chem. Toxicol. 29:537-547.

Gäde, G., Hoffmann, K. H., and Spring, J. H. 1997. Hormonal regulation in insects: Facts, gaps, and future directions. Physiol. Rev. 77:963-1032

Grebenok, R. J., and Adler, J. H. 1993. Ecdysteroid biosynthesis during the ontogeny of spinach leaves. Phytochemistry 33:341-347.

Gustafson, V., Mallubhotla, S., MacDonnell, J., Sanyal-Bagchi, M. Chakravarty, B., Wang-Pruski, G., Rothwell, C., Audy, P., De Koeyer, D. and Siahbazi, M. 2006. Transformation and plant regeneration from leaf explants of Solanum tuberosum L. cv. 'Shepody'. Plant Cell Tissue Organ Cult. 85:361-366.

Hare, D. J. 1980. Impact of defoliation by the Colorado potato beetle on potato yields. J. Econ. Entomol. 73:369-373.

Henriquez, M. A., Adam, L. R., and Daayf, F. 2012. Alteration of secondary metabolites' profiles in potato leaves in response to weakly and highly aggressive isolates of Phytophthora infestans. Plant Physiol. Biochem. 57:8-14.

Hollister, B., Dickens, J. C., Perez, F., and Deahl, K. L. 2001. Differential neurosensory responses of adult Colorado potato beetle, Leptinotarsa decemlineata, to glycoalkaloids. J. Chem. Ecol. 27:1105-1118.

Itkin, M., Heinig, U., Tzfadia, O., Bhide, A. J., Shinde, B., Cardenas, P. D., Bocobza, S. E., Unger, T., Malitsky, S., Finkers, R., Tikunov, Y., Bovy, A., Chikate, Y., Singh, P., Rogachev, I., Beekwilder, J., Giri, A. P., and Aharoni, A. 2013. Biosynthesis of antinutritional alkaloids in solanaceous crops is mediated by clustered genes. Science 341:175-179.

Itkin, M., Rogachev, I., Alkan, N., Rosenberg, T., Malitsky, S., Masini, L., Meir, S., Iijima, Y., Aoki, K., de Vos, R., Prusky, D., Burdman, S., Beekwilder, J., and Aharoni, A. 2011. GLYCOALKALOID METABOLISM1 is required for steroidal alkaloid glycosylation and prevention of phytotoxicity in tomato. Plant Cell 23:4507-4525.

Kaplan, E. L., and Meier, P. 1958. Nonparametric estimation from incomplete observations. J. Am. Stat. Assoc. 53:457-481.

Kessler, A. 2015. The information landscape of plant constitutive and induced secondary metabolite production. Curr. Opin. Insect Sci. 8:47-53.

Keukens, E. A. J., de Vrije, T., van den Boom, C., de Waard, P., Plasman, H. H., Thiel, F., Chupin, V., Jongen, W. M. F., and de Kruijff, B. 1995.
Molecular basis of glycoalkaloid induced membrane disruption. BBABiomembranes 1240:216-228.

Kim, J., and Kinghorn, A. D. 1989. Further steroidal and flavonoid constituents of the sweet plant, Polypodium glycyrrhiza. Phytochemistry 28:1225-1228.

Kim, J., Pezzuto, J. M., Soejarto, D. D., Lang, F. A., and Kinghorn, A. D. 1988. Polypodoside A, an intensely sweet constituent of the rhizomes of Polypodium glycyrrhiza. J. Nat. Prod. 51:1166-1172.

Kowalski, S. P., Domek, J. M., Deahl, K. L., and Sanford, L. L. 1999. Performance of Colorado potato beetle larvae, Leptinotarsa decemlineata (Say), reared on synthetic diets supplemented with Solanum glycoalkaloids. Am. J. Potato Res. 76:305-312.

Lafont, R., Dauphin-Villemant, C., Warren, J. T., and Rees, H. 2012. Ecdysteroid chemistry and biochemistry. Pages 106-176 in: Insect Endocrinology. Academic Press, San Diego, CA, U.S.A.

Lafont, R., Harmatha, J., Marion-Poll, F., Dinan, L., and Wilson, I. 2002. Ecdybase. The Ecdysone Handbook. Cybersales, Praha, Czech Republic.

Lorenzen, J. H., Balbyshev, N. F., Lafta, A. M., Casper, H., Tian, X., and Sagredo, B. 2001. Resistant potato selections contain leptine and inhibit development of the Colorado potato beetle (Coleoptera: Chrysomelidae). J. Econ. Entomol. 94:1260-1267.

Marciniak, P., Adamski, Z., Bednarz, P., Slocinska, M., Ziemnicki, K., Lelario, F., Scrano, L., and Bufo, S. A. 2010. Cardioinhibitory properties of potato glycoalkaloids in beetles. Bull. Environ. Contam. Toxicol. 84:153-156.

Maria, A., Girault, J.-P., Saatov, Z., Harmatha, J., Dinan, L., and Lafont, R. 2005. Ecdysteroid glycosides: Identification, chromatographic properties, and biological significance. J. Chromatogr. Sci. 43:149-157.

McCue, K. F., Allen, P. V., Shepherd, L. V. T., Blake, A., Maccree, M. M., Rockhold, D. R., Novy, R. G., Stewart, D., Davies, H. V., and Belknap, W. R. 2007. Potato glycosterol rhamnosyltransferase, the terminal step in triose side-chain biosynthesis. Phytochemistry 68:327-334.

Milner, S. E., Brunton, N. P., Jones, P. W. O., O’Brien, N. M., Collins, S. G., and Maguire, A. R. 2011. Bioactivities of glycoalkaloids and their aglycones from Solanum species. J. Agric. Food Chem. 59:3454-3484.

Mithöfer, A., and Boland, W. 2012. Plant defense against herbivores: Chemical aspects. Annu. Rev. Plant Biol. 63:431-450.

Morrissey, J. P., and Osbourn, A. E. 1999. Fungal resistance to plant antibiotics as a mechanism of pathogenesis. Microbiol. Mol. Biol. Rev. 63:708-724.

Munafo, J. P., Jr., and Gianfagna, T. J. 2015. Chemistry and biological activity of steroidal glycosides from the Lilium genus. Nat. Prod. Rep. 32:454-477.

Mustafa, M. K., and Dyakov, Y. T. 1991. The effect of alpha-tomatin on the viability of the phytopathogenous fungus Phytophthora infestans (Mont.) De Barry and its interaction with potato. Mosc. Univ. Biological Sci. Bull. 46:16-20.

Mweetwa, A. M., Hunter, D., Poe, R., Harich, K. C., Ginzberg, I., Veilleux, R. E., and Tokuhisa, J. G. 2012. Steroidal glycoalkaloids in Solanum chacoense. Phytochemistry 75:32-40.

Neilson, E. H., Goodger, J. Q. D., Woodrow, I. E., and Møller, B. L. 2013. Plant chemical defense: At what cost? Trends Plant Sci. 18:250-258.

Nema, P. K., Ramayya, N., Duncan, E., and Niranjan, K. 2008. Potato glycoalkaloids: Formation and strategies for mitigation. J. Sci. Food Agric. 88:1869-1881

Nielsen, J. K., Nagao, T., Okabe, H., and Shinoda, T. 2010. Resistance in the plant, Barbarea vulgaris, and counter-adaptations in flea beetles mediated by saponins. J. Chem. Ecol. 36:277-285.

Obidiegwu, J. E., Bryan, G. J., Jones, H. G., and Prashar, A. 2015. Coping with drought: Stress and adaptive responses in potato and perspectives for improvement. Front. Plant Sci. 6:542.

Pelletier, Y., Horgan, F. G., and Pompon, J. 2013. Potato resistance against insect herbivores: Resources and opportunities. Pages 439-462 in: Insect Pests of Potato. Adacemic Press, New York.

R Core Team. 2016. R: A language and environment for statistical computing. R Foundation for Statistical Computing, Vienna, Austria.

Roddick, J. G. 1989. The acetylcholinesterase-inhibitory activity of steroidal glycoalkaloids and their aglycones. Phytochemistry 28: 2631-2634.

Roddick, J. G., and Rijnenberg, A. L. 1986. Effect of steroidal glycoalkaloids of the potato on the permeability of liposome membranes. Physiol. Plant. 68:436-440.

Sablon, L., Dickens, J. C., Haubruge, É., and Verheggen, F. J. 2012. Chemical ecology of the Colorado potato beetle, Leptinotarsa decemlineata (Say) (Coleoptera: Chrysomelidae), and potential for alternative control methods. Insects 4:31-54

Savchenko, T., Whiting, P., Germade, A., and Dinan, L. 2000. Ecdysteroid agonist and antagonist activities in species of the Solanaceae. Biochem. Syst. Ecol. 28:403-419. 
Sawai, S., Ohyama, K., Yasumoto, S., Seki, H., Sakuma, T., Yamamoto, T., Takebayashi, Y., Kojima, M., Sakakibara, H., Aoki, T., Muranaka, T., Saito, K., and Umemoto, N. 2014. Sterol side chain reductase 2 is a key enzyme in the biosynthesis of cholesterol, the common precursor of toxic steroidal glycoalkaloids in potato. Plant Cell 26:3763-3774.

Simons, V., Morrissey, J. P., Latijnhouwers, M., Csukai, M., Cleaver, A., Yarrow, C., and Osbourn, A. 2006. Dual effects of plant steroidal alkaloids on Saccharomyces cerevisiae. Antimicrob. Agents Chemother. 50:2732-2740.

Sinden, S. L., Sanford, L. L., Cantelo, W. W., and Deahl, K. L. 1986. Leptine glycoalkaloids and resistance to the Colorado potato beetle (Coleoptera: Chrysomelidae) in Solanum chacoense. Environ. Entomol. 15:1057-1062.

Smith, C. A., O’Maille, G., Want, E. J., Qin, C., Trauger, S. A., Brandon, T. R., Custodio, D. E., Abagyan, R., and Siuzdak, G. 2005. METLIN: A metabolite mass spectral database. Ther. Drug Monit. 27:747-751.

Spindler, K.-D., Hönl, C., Tremmel, Ch., Braun, S., Ruff, H., and SpindlerBarth, M. 2009. Ecdysteroid hormone action. Cell. Mol. Life Sci. 66: 3837-3850.

Sun, W., and Sneng, J. 1998. Brief handbook of natural active compounds. Medicinal Science and Technology Press of China, Beijing.

Szczepanik, M., Bialy, Z., and Jurzysta, M. 2004. The insecticidal activity of saponins from various Medicago spp. against Colorado potato beetle, Leptinotarsa decemlineata Say. Allelopathy J. 14:177-185.

Tai, H. H., Conn, G., and Stairs, C. 2009. Arbitrary reference for real-time PCR gene expression analysis. Plant Mol. Biol. Report. 27:315-320.
Tai, H. H., Williams, M., Iyengar, A., Yeates, J., and Beardmore, T. 2007. Regulation of the $\beta$-hydroxyacyl ACP dehydratase gene of Picea mariana by alternative splicing. Plant Cell Rep. 26:105-113.

Tai, H. H., Worrall, K., De Koeyer, D., Pelletier, Y., Tai, G. C., and Calhoun, L. 2015. Colorado potato beetle resistance in Solanum oplocense X Solanum tuberosum intercross hybrids and metabolite markers for selection. Am. J. Potato Res. 92:684-696.

Tai, H. H., Worrall, K., Pelletier, Y., De Koeyer, D., and Calhoun, L. A. 2014. Comparative metabolite profiling of Solanum tuberosum against six wild Solanum species with Colorado potato beetle resistance. J. Agric. Food Chem. 62:9043-9055.

Tingey, W. M. 1984. Glycoalkaloids as pest resistance factors. Am. Potato J. 61:157-167.

Van Gelder, W., Vinke, J., and Scheffer, J. 1988. Steroidal glycoalkaloids in tubers and leaves of Solanum species used in potato breeding. Euphytica 39:147-158.

Wierenga, J. M., and Hollingworth, R. M. 1992. Inhibition of insect acetylcholinesterase by the potato glycoalkaloid $\alpha$-chaconine. Nat. Toxins 1:96-99.

\section{AUTHOR-RECOMMENDED INTERNET RESOURCES}

Cran R survival package: https://CRAN.R-project.org/package=survival Ecdybase database: http://ecdybase.org Multiple Experiment Viewer: http://mev.tm4.org 